Kalpa Publications in Civil Engineering
Volume 1, 2017, Pages 336-342
$\begin{gathered}\text { ICRISET2017. International Conference on Re- } \\ \text { search and Innovations in Science, Engineering } \\ \text { \&Technology. Selected papers in Civil Engineering }\end{gathered}$

\title{
Municipal Solid Waste Management of Medium Scale Town of South Gujarat Region
}

\author{
Miss. Anjali Prajapati ${ }^{12 *}$ and Dr. Arti Pamnani ${ }^{12 \dagger}$ \\ ${ }^{1}$ Department of Civil (Environmental) Engineering, $M$ tech \\ ${ }^{2}$ BVM engineering College, ${ }^{2} \mathrm{~B}$ \& B Institute of Technology Vallabh Vidyanagar, Anand, India, \\ anjaliprajapati27@gmail.com,artnitnan@yahoo.com
}

\begin{abstract}
In Municipal solid waste disposal is a burning issue around the world. Increase of the population and change in lifestyle are finding their way out to manage for a fight quantum increase in MSW. Due to least priority of the governing body in developing country like India, it is much tougher to have a sustainable management system for MSW. Town in India is characterizing as per population. This paper gives detail studied with segregation and sustainable management of waste composition was suggested for MSW in the medium scale town of the south Gujarat region in India. Route study of the MSW transportation is also done so as optimum route can be suggested with the quantity of waste in minimum cost.
\end{abstract}

\section{Introduction}

The solid waste generation increase with increase human population and the change in modern lifestyle, for that resulting in the contamination of air, water and land resources (Salunke, et al., 2016, Komal et al., 2014). Residential, industrial, commercial, institutional, construction, agricultural and municipal process are eight most important activities of human as well as cattle through solid waste is generated (Basavaraj, et al., 2015; Bhambulkar, et al., 2011; Edema et al., 2012). It's classified as different municipal solid waste materials in this includes Organic waste like - cooked and uncooked food, fruits and flowers, etc., Household biomedical waste like - diaper, napkin, medicine, etc., Household hazardous waste like -paint drums, pesticide cans, florescent lamps, Ni-Cd batteries, needles and Recycle waste like - plastics, rubber, metals, glass, newspapers etc. (Municipal solid waste (segregation) rules 2000) (Odile et al., 2008).

Municipal solid waste management has emerged as scientifically, economically, and socially has attracted by an imposed urban environmental issue and over the year developed into an independent

\footnotetext{
* Masterminded EasyChair and created the first stable version of this document

${ }^{\dagger}$ Created the first draft of this document
}

C.D. Modhera, G.J. Joshi, D. Soni, I.N. Patel, A.K. Verma, L.B. Zala, S.D. Dhiman, D.R. Bhatt, J.M. Rathod, B.C. Goradiya, M.S. Holia and D.K. Patel (eds.), ICRISET2017 (Kalpa Publications in Civil Engineering, vol. 1), pp. 336-342 
control. However, the waste management system in the third world city has either collapse or is nonexistent altogether. The seven measures composition of the solid waste management system is follows as waste generation, storage, collection, transfer, transport, processing, and disposal (Ch. Bhavannarayana, et al., 2014).

Generally, high percentage of compostable organic matter has generated all low and middleincome countries in the urban waste stream, ranging from 45 to $85 \%$ of the total (IBRD/The World Bank, 1999) (Arvind et al., 2013). Anticipation and manages of Waste diminishment and reuse for both items strategies are the arranging of solid waste management for streamlining of courses, gathering and transfer of solid (Hiral, 2016).

\section{Selection of study area}

It is found that the studies has been mostly carried out in metropolitan and large scale town municipality and gives financial support from government for public cleanness and awareness of solid waste and a sufficient number of trained personnel as compared to small and medium scale town for solid waste management. Due to less awareness amongst the public in small and medium scale town are neglected in infrastructure development and other amenities (Arti, 2015). A study on waste management and character is right full directions to municipal corporations and population management in medium scale town of Gujarat state. Based on population, the urban housing development Gujarat has classified town in following categories: small town- 5000-20000 of population, Small town II - 20000-50000 of population, Medium scale I- 50000-100000 of population, Medium scale town II- 1lakh-5lakh of population, Large city- 5lakh-10lakh of population, Metropolitan city I- 10lakh-50lakh of population, metropolitan city II- 50lakh - 1crore of population, Mega polish - above 1crore of population. There are 73 Small-scale towns II, 28 medium scale towns I, 24 Medium scale towns II, 2 large cities, 3 Metropolitan cities I, 1 Metropolitan city II exists in the state of Gujarat data according to census, 2011.

For study purposes, Valsad municipal corporation is selected in Valsad district of Gujarat state because Valsad municipal corporation is not yet studied, scientifically and technically for MSWM of existing facilities and method is done and further detailed study of waste character is done for better waste management system. MSW management and handling rules in the year2000 had issued by the Ministry of Environment and Forest (MoEF) government of India for scientific MSWM. Whereas MSWM as a poor service compared to other basic services this was shown by local authorities. Therefore, MSWM can barely recover operating costs (Arti, 2015). Due to many management problems, they have not been very effective during proper collection, segregation, transportation, processing and disposal of MSW and upgrade of the existing facilities to arrest contamination of soil and ground water.

\section{Study area}

Valsad is located in the southern part of Gujarat state. Valsad city total geographical area of $13.4 \mathrm{sq} \mathrm{km}$. Valsad is located at $20.63^{\circ} \mathrm{N}$ and $72.93^{\circ} \mathrm{E}$. It has an average elevation of 13 meters $(42$ feet).The city canter is about $4 \mathrm{~km}$ inland from the Arabian sea, as valsad is near the sea so in the city has uniform temperature throughout the year. In Valsad, average temperature around $29^{\circ} \mathrm{C}$ during the day in winter season, while the night time tends to be dropped down to $11^{\circ} \mathrm{C}$ on average and in summer season average temperature $40^{\circ} \mathrm{C}$ during the day, while the night time $30^{\circ} \mathrm{C}$. The humidity during monsoon period is high and varies from $75 \%$, while the sun rise increase $5-6 \%$. The humidity is low during winter season varies from $42 \%$ to $69 \%$. According to 2011 census valsad town 
population is 145592 persons and households is 44434. See here below figure no. 2 in which since 1951, decade wise population mentioned. As per official records there has been found that the rapid growth of population was high migration and natural growth. Valsad city differentiates in 14 wards. In valsad summer, climate has a hot and humid and winter climate has cold and dry. During monsoon an average rainfall is $2160 \mathrm{~mm}$.

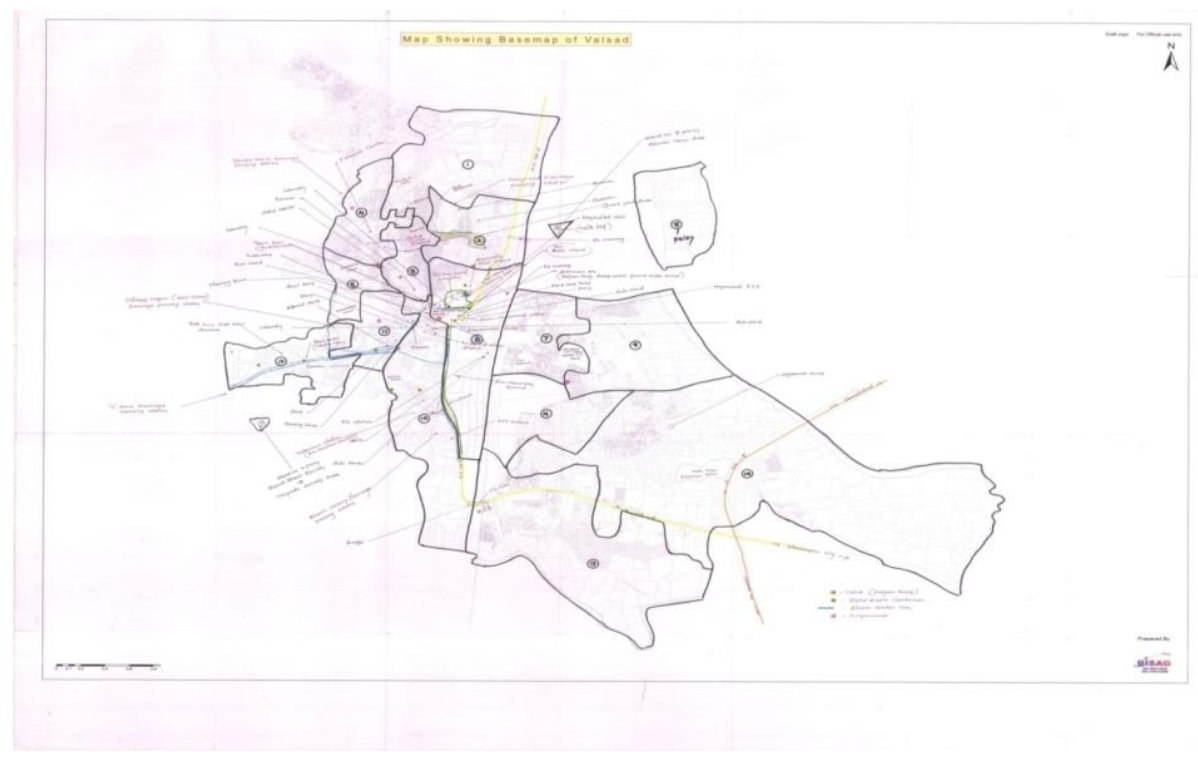

Fig1 Ward wise map of study area

Municipal waste management in required climatic factor for study because is directly affected the solid waste. During the monsoon season, heat and humidity cause the wet organic waste of MSW to be higher moisture content thus increasing the weight of the refuse. In addition, quickly decompose for required high humidity with heat to degrade the organic portion of the waste which is problems in MSWS, which directly affects MSWS worker health and that around environmental inhabitants (Pratrick, 2015, Arti, 20

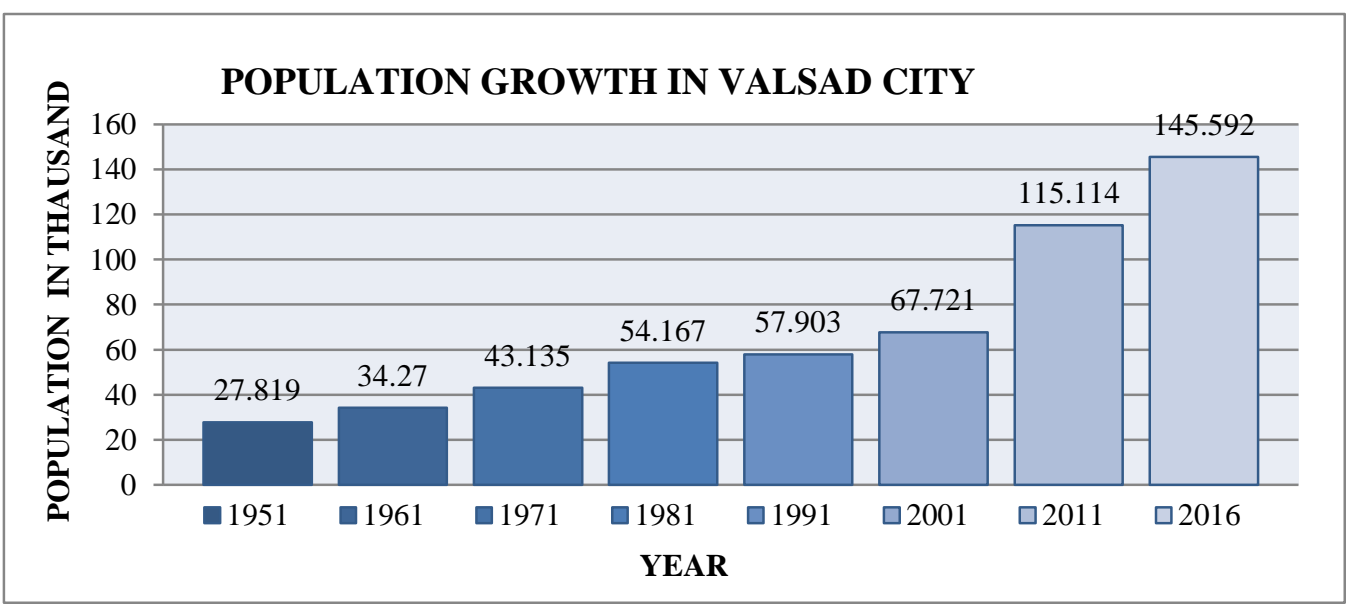

Fig 2 population growth of Valsad city 


\section{Currently used municipal solid waste management system}

In this detail study is carried out for existing solid waste management system by the Valsad municipal corporation authorities. The people live in the Valsad city are produced 50 MTPD solid wastes from different sources such as household medical, domestic, industrial, demolition construction, agriculture, offices and schools. VMC is working for collection, transportation and disposal of municipal solid waste in the city area form $7 \mathrm{am}$ to $6 \mathrm{pm}$. The VMC concerned sanitary inspector has taking attendance of their sweeping staff as well as the collection staff at the particular word cabin. Their normal working hours is from 8.00 a.m. to 12.00 a.m. \& 1.30 p.m. to 6 p.m. The buckets are normally used by sweepers for transporting silt removed from drains. This all activates for assigned specific area to sweeper. However the waste often remains uncollected from streets to get deposited at open collection points as there are no individual activities supervision over the workers. One sanitary inspector and 265 persons are provided for over all sanitation of the town which includes municipal solid waste management. The total 8 hours per day for municipal solid waste collection and distance to be covered $13.4 \mathrm{~km}$ (Bhambulkar et al., 2011). In the city area less than $80 \%$ (12) wards in door to door collection is done and street sweeping waste collection process and 2 wards in solid waste collected once in a two days. The government of Gujarat provided 5 small collectors to Municipal Corporation for municipal solid waste collection. In the collection time waste is primary segregated manually to dry (recycle, reuse) waste and wet (cooked food) waste and also 44 collection points covered through tractor. After these remaining waste is thrown in low line area. Low line area is considered as open dumping site located near Oranga river bank which is situated in the area of 3 acres.

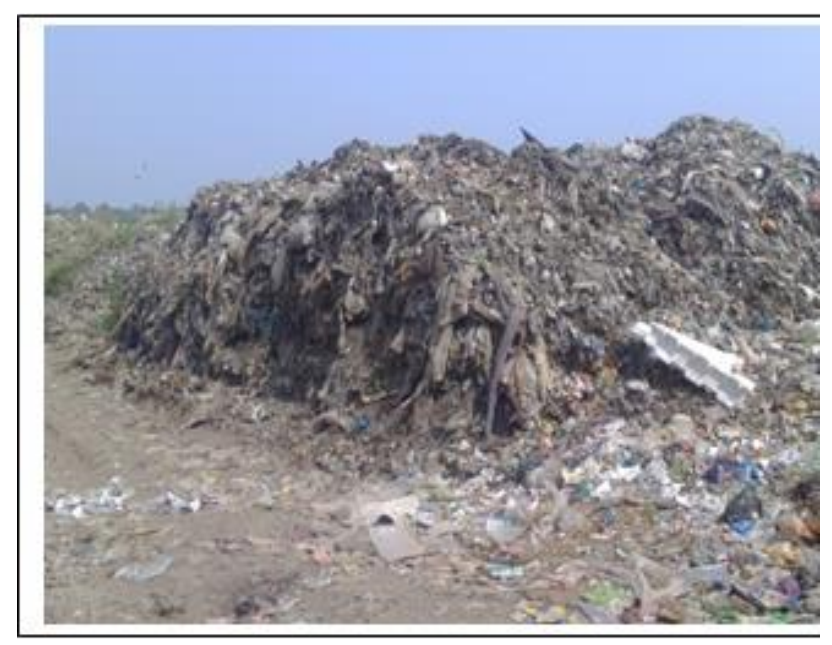

Figure 3 Location of open dumping site near the Oranga river bank

Where the secondary segregation is done and separate out recycled and reuse waste (toys, plastic bottle) by rag picker and selling recycles waste to scrapper in $2 \mathrm{Rs} / \mathrm{kg}$ and earning money. Open dumping site no scientific care is taking of the site nuisance of insects, flies and leached is found at the dumping site. Area near the dumping site has bad odour and unwanted site. Due to unscientific disposal causes an adverse impact surrounding environment and human health. There are 44 large bins placed in entire town at different location at residential and commercial and institutional area. Such a factor like eating habits, measures of quality of life, degree of commercial activities and seasons affected the amount of MSW production (Salunke et al., 2016; Arti, 2015; Swapan et al., 2013). 


\section{Suggested methods}

1. Suitable appropriate biological processing for biodegradable waste such as technics like composting, vermicomposting, anaerobic digestion or any other should be adopted by municipal authorities. By these technics stabilized waste and minimize burden on landfill sites.

2. The product collected is the most common consumer as a recycle and reuse waste in include aluminum beverage can, copper wire, food packages made from steel and eatable oil jars, empty bottles from PVC, empty bottles and jars made by glass, cartons of paper, used newspapers, used magazines and light paper, and fiberboard boxes are made, can be used for reprocess and making into other new products. Waste sorted directly from mixed waste streams. Material for recycling should be collected separately from general municipal solid waste through using color coding bins like green for recycle waste, red for household medical waste, grey for organic waste, yellow for household hazardous waste.

3. This municipal solid waste is the source of energy but normally Municipal Corporation can be treated as waste. The solid waste is having calorific value by heating and produced the electricity from this energy. Environmental quality and lifestyle of city dwellers improve through MSW disposal recovered energy from the waste that problem could be solved by WTE (Waste to Energy). It is estimated that, for electricity production required more than $70 \%$ of food or vegetable waste with more than $60 \%$ moisture content this value achieved a high calorific value from MSW. Subsequently, electricity generation for MSW can be used as other possible sources in VMC.

\section{Conclusion}

Form research it is found that most difficult task in medium town/municipal corporation is proper study of waste. So, this research methodology will give proper method of collection, transportation, disposal and treatment. The solid waste is collected in plastic bags or dustbin by people and dispersed that in open location or drain it in river. The street is sweeping by Sweepers. Whereas rag pickers collected recyclables waste from open collection point. Mostly generated waste storage in the vacant area or vehicle approachable side. Different places to the disposal site was transport solid waste for used vehicles are not covered. Nearly $75-80 \%$ of the waste deliver by transporting to reserve for solid waste dumping area near the bank of river Oranga, where it is to be burned openly carried out resulting in land, air and water pollution. As well as after long time the process leachate percolation through land and contaminate the quality of ground water at near dumping site.

The waste generation minimized at source, composition of waste into organic waste, recycle waste, household biomedical waste, household hazardous waste before its disposal. The following fundamental principles of four R`s (Reduce, Reuse, Refuse, Recycle) and awareness among the mass are some of the measures which can help in oppose the problem of solid waste in the study area. Everything flows in a natural cycle of use and reuse no such a thing as waste. Living organisms consume materials and eventually back to the environment, usually in a different form. Human concept for solid waste is reuse because solid waste is worthless for one person but this waste is valuable for other one. Techniques like sanitary landfill, incineration, composting etc. should be adopted for reuse. Middle range collection point to landfill for waste collection time must be maintained and waste disposal for new transfer station is appointed in different area. Besides, developing location of the collection points as well as in the landfill area by used of Geographical Information System (GIS) tool kit. Vehicle for transportation of solid waste should be coved.

Integrated solid waste gives a better solution for management of organic and inorganic waste of organic waste coming out of medium scale town. Vermicomposting can be a better treatment as it gives manure from the waste, which can be utilized for improvement of solids for agriculture. As calorific 
value of organic municipal solid waste is found to be high, it can be utilize as alternate fuel for industrial purpose provided by the drop down menu to differentiate the head from the text.

\section{Acknowledgment}

I express my deep sense of gratitude to my highly esteemed guide, Dr ARTI N PAMNANI (Lecturer, Civil Engineering Department) for her encouragement and constructive support and suggestions. I would like to thank my family for allowing me to realize my own potential and guiding me at all stages of my experiment work.

\section{References}

Carlisle, A. Moreno, M. Rodriguez, A. Velasco, J. Enriquez, A. Hernandez, et al., "Mexico City's Municipal Solid Waste Characteristics and Composition Analysis," Rev. Int. Contam.Ambie.29 (1), PP 39-46.,2013.

A. Kumar, S. Singh,"Domestic Solid Waste Generation - A Case Study of Semi-Urban Area of Kathua District, Jammu, J\&K, India," International Journal of, Scientific and Research Publications, Vol. 3, Issue 3, pp.1-5, 2013.

A. Pamnani, "Management of Municipal Solid Waste: A Study of Small Scale Municipality," International Journal of Engineering Sciences and Research Technology, January, Vol. 4, pp.19$24,2015$.

A.V. Bhambulkar, I. Khedikar, "Municipal Solid Waste Collection Route for Laxmi Nagar, Pune by Geographical Information System," International Journal of Advanced Engineering Technology, Vol. 2, Issue 4, pp. 48-53,2011.

B. Itnal, S Prakash, "Route Optimization of Community Solid Waste Management in Selected Wards of Bangalore City Using Geological Information System (GIS),".International Journal of Research in Engineering and Technology, Vol. 04, Issue 11, pp.232-238,2015.

Ch. Bhavannarayna, K. Prakash, V. Saritha, "Estimate of Municipality Solid Waste Generation A Case Study of Kovvur City in Andhra Pradesh," International Journal of Research and Reviews in Pharmacy and Applied Science, Vol. 2, Issue 3,2012.

D. Eheliyagoda, N. Prematilake, "Assessment of a Planned Municipal Solid Waste Management System in Sri Lanka," Journal Applied Science Environment Manage, Vol.20 (1), pp.58-61,2016.

Dr. K. Mehta; Mrs H. Pandey, "Status of Solid Waste in City of Vadodara," International Journal of Darshan Institute on Engineering Research and Emerging Technology, Vol. 3, No.1, pp.2428,2014 .

Edema, Mojisola O, S. Victor, Ntengwe Felix W., "Solid Waste Management- Case Study of Ndola, Zambia,"International Journal of Plant, Animal, and Environmental Sciences, Vol. 2, Issue 3, pp.248-255, 2012.

Integrated Modelling of Solid Waste in India.

Ministry of Environment and Forests. Notification on "Municipal Solid Wastes (Management and Handling) Rules 2000.

Mr. H. Patel, Prof. H. Padya, Prof. P.Zaveri, "GIS Based Route Optimization for Solid Waste Management: A Case Study of Surat City,"International Journal for Scientific Research and Development, Vol. 4, Issue 4, pp.32-35,2016.

Ms. A.A. Salunke, Dr. M. Husain, F.I. Chavan, "Solid Waste Management for Dhule City," International Conference on Global Trends in engineering, Technology and management, 2016. 
O. Schwarz-Herion, A. Omran, Hans Peter Rapp, "A Case Study on Successful Municipal Solid Waste Management in Industrialized Countries by the Example of Karlsruhe City, Germany,"Journal of Engineering Tome 6, Fascicule 3, pp.266-273,2008. 